\title{
Análisis de la realidad de las mujeres en situación o riesgo de exclusión social en la Comunidad Autónoma de Euskadi
}

\section{Sonia Carrasco Fernández}

Departamento de Economía Aplicada I, Universidad del País Vasco (UPV/EHU) <sonia.carrasco@ehu.eus>

Artikulu honetan nahiko genuke pobrezia eta gizartebazterketa pairatzen duten emakumeen errealitatea erakutsi, eta horretarako aztergai hartzen dira emakume horienak diren diskurtso eta testigantzak. Gure asmoa izan da erakusgarri gertatzea kaltebera eta baztertuak dauden emakumeen egoera horiek, eta informazio hori baliatu dugu sakondu ahal izateko pobrezia- eta bazterkeria-egoera horien kausa, ondorio eta faktore gisara, betiere, egungo errealitatea sakonean ezagutzeko asmoz.

\section{GAKO-HITZAK:}

Genero-desberdintasuna, gizarte-bazterketa, pobrezia, bazterkeria-faktoreak.
En este artículo, quisiéramos mostrar la realidad de las mujeres en situación de pobreza y exclusión social, analizando para ello los discursos y testimonios de las propias mujeres. Hemos dado voz a las mujeres que viven situaciones de vulnerabilidad y exclusión social, y hemos utilizado esta información para profundizar en las causas, consecuencias y en los factores que conducen a esas situaciones de pobreza y exclusión social, intentando conocer en profundidad su realidad más actual.

\section{PALABRAS CLAVE:}

Desigualdad de género, exclusión social, pobreza, factores de exclusión. 


\section{Introducción}

El objetivo del presente artículo es mostrar los resultados preliminares de la investigación que estamos llevando a cabo en el marco de una tesis doctoral realizada en la Universidad del País Vasco / Euskal Herriko Unibertsitatea (UPV/EHU), titulada "Pobreza y exclusión social desde la perspectiva de género en la Comunidad Autónoma de Euskadi: analizando los procesos de empobrecimiento y exclusión social de las mujeres a través de sus discursos (2008-2016)".

El III Plan Vasco de Inclusión Activa (2012-2016) señala que la pobreza, en la Comunidad Autónoma de Euskadi (CAE), tiene rostro de mujer. Explica que son mujeres más de dos tercios de las personas perceptoras de renta básica y que la población femenina no sólo es dominante entre los colectivos más pobres ( $53 \%$ ), sino también, de forma general, en cuanto a la pobreza o ausencia de bienestar (57\%). También señala que hay un aumento de la población inmigrante empadronada, respecto a la cual el $48 \%$ son mujeres, y que las medidas de conciliación son mayoritariamente utilizadas por las mujeres y, por tanto, pueden tener un efecto perverso en su avance profesional y personal. Teniendo en cuenta estos datos, queremos visibilizar en este artículo los factores que causan la situación de pobreza y exclusión social de las mujeres, intentando conocer en profundidad su realidad más actual.

Para analizar la realidad en clave feminista, debemos tener en cuenta tres elementos importantes. En primer lugar, la multidimensionalidad desde la que se plantea la pobreza y exclusión social de las mujeres. Las múltiples dimensiones y caras de la pobreza y la exclusión social es una de las ideas compartidas por la literatura especializada en estos procesos, tal y como queda en evidencia en la revisión sistemática de estudios y trabajos específicos realizada en el marco de nuestra investigación. Esta multidimensionalidad aparece además continuamente en los relatos y testimonios de las mujeres, cuando nos cuentan sus diferentes experiencias en torno a la pobreza y exclusión social. En segundo lugar, la interseccionalidad es un elemento importante para entender las diferentes situaciones de discriminación y los diferentes roles que se les asigna a hombres y mujeres en nuestra sociedad, y que se trasladan a las situaciones de pobreza y exclusión social. En tercer y último lugar, la diferente posición que tienen hombres y mujeres en la sociedad es otro elemento de análisis clave de nuestra investigación. Esta posición alude a la desventajosa ubicación social, económica, política y cultural que tienen las mujeres respecto a los hombres, y que se traduce en menores oportunidades de empleo y salario, y en mayor vulnerabilidad frente a la pobreza y la violencia, entre otras cuestiones.

Partiendo de este enfoque, el presente artículo se ha estructurado en tres partes:
- En la primera, expondremos el marco teórico utilizado, donde, a través de autores/as expertos/as en exclusión social y pobreza, analizamos los factores causales que llevan al empobrecimiento y la exclusión social de las mujeres en comparación con los hombres. Analizaremos la pobreza y la exclusión social desde el género, así como la relación entre los procesos de empobrecimiento y el género.

- En la segunda, a la vista de las limitaciones e insuficiencias que encontramos en los estudios actuales sobre pobreza y exclusión social en la CAE desde el punto de vista del género, explicaremos por qué hemos realizado una investigación focalizada sobre la situación de las mujeres en riesgo o situación de exclusión, que identifique la situación de privación de las mujeres en relación con los hombres. Expondremos las limitaciones y carencias que se han encontrado en los análisis y datos estadísticos oficiales en cuanto al género, y explicaremos la ‘ceguera de género' de estos análisis.

- En la tercera, expondremos los resultados preliminares de la investigación obtenidos a través de los relatos y testimonios de las mujeres que viven situaciones de vulnerabilidad y exclusión social y que han participado en este trabajo de investigación. Para ello, hemos utilizado la metodología cualitativa, a través de grupos focales con mujeres que son atendidas en entidades sociales de la CAE y que, voluntariamente, han aceptado participar en la investigación. Nos introduciremos en el análisis de la realidad de las mujeres en situación o riesgo de exclusión social a través de los testimonios recogidos en estos grupos. Los grupos focales se han realizado en colaboración con nueve entidades sociales que trabajan en el ámbito de la exclusión social con mujeres.

Hemos prestado especial atención a las verdaderas protagonistas de este estudio, las propias mujeres $y$, a través de sus percepciones, opiniones y testimonios, hemos tratado de explicar y comprender su realidad. Lo que nos interesaba era profundizar y analizar los procesos de exclusión (e inserción) social, sus causas y sus consecuencias, los factores influyentes, las barreras y obstáculos para conseguir su inclusión y participación en la sociedad como ciudadanas de pleno derecho. El objetivo era realizar un diagnóstico detallado, rico y profundo de su situación.

Para llevar a cabo los grupos focales, se ha trabajado conjuntamente con la Red de Lucha contra la Pobreza y la Exclusión Social en Euskadi (EAPN Euskadi). Gracias a ella, hemos podido acceder a las entidades sociales que conforman la red y que trabajan con mujeres en riesgo o situación de exclusión social. 


\section{Factores causales de la exclusión social desde la perspectiva de género}

La pobreza y la exclusión social no siempre se han analizado desde una perspectiva de género, lo que hace que la información sobre ambos fenómenos esté incompleta y cuente con sesgos, puesto que oculta realidades que no se analizan, como las distintas situaciones de vulnerabilidad o los distintos factores de riesgo que afectan a las mujeres en comparación con los hombres.

Diversos estudios plantean la necesidad de estudiar la pobreza y la exclusión social con enfoque de género (entre ellos, Tortosa, 2001; y De la Cal, 2009). La pobreza y la exclusión están condicionadas por las identidades de género, por lo que debemos analizar a hombres y mujeres desde sus diferentes intereses, responsabilidades y oportunidades (Brunet, Valls y Belzunegui, 2008). Desde esta posición, queremos analizar cómo los procesos de empobrecimiento y vulnerabilidad afectan a hombres y mujeres de modo diferencial.

Tenemos que resaltar que las desigualdades de género configuran la vida de hombres y mujeres en aspectos como la renta, la jornada laboral o el uso del tiempo y que debemos transformar las relaciones de género si queremos mejorar la vida de las mujeres (Robeyns, 2003; Brunet, 2009). En este sentido, prestar una especial atención a las relaciones de género es esencial para comprender la situación social y económica de las mujeres.

Es importante reconocer que, en la CAE, las políticas de lucha contra la pobreza y la exclusión social han tenido una gran incidencia en los procesos de reducción de la pobreza de la población en general, mediante un sistema de asistencia contributiva y no contributiva y de un sistema de protección general de los hogares empobrecidos a través de las rentas mínimas. Aun así, también en nuestra comunidad autónoma algunos colectivos reciben proporcionalmente una menor cobertura, entre ellos, las mujeres, cuya situación económica está amenazada por los siguientes factores (Brunet, 2009; Laparra, 2010):

- Posición en el mercado laboral.

- Escaso acceso a la protección contributiva.

- Posición en el trabajo reproductivo y de cuidados.

\subsection{Posición en el mercado laboral}

Aunque en las últimas décadas han alcanzado un mayor acceso a los recursos económicos y han logrado un mayor control sobre ellos, las mujeres, como colectivo, siguen manteniendo unos niveles de privación de recursos económicos (ingresos) elevados y una insatisfacción en su cobertura de las necesidades humanas básicas que limitan el desarrollo de sus capacidades (Frau, 2001; Nussbaum, 2012; Damonti, 2014).
Merece la pena señalar aquí, a modo de contextualización, que el trabajo no sólo es importante como forma de acceso a recursos económicos, sino que además adquiere una gran relevancia en el plano social, es decir, "es una forma de participación de gran significación social" (Frau, 2001: 113). Existe una clara división dependiendo de si se obtiene remuneración, o no, por el trabajo realizado. Por lo tanto, dependiendo del trabajo que se realice, de si es remunerado o no, éste será valorado socialmente de forma desigual, adquiriendo una mayor significación social los trabajos que se desarrollan en los sectores monetizados (en el mercado).

Las sociedades actuales valoran la obtención de ingresos económicos y la capacidad de las personas para obtenerlos, por lo que el trabajo no mercantilizado, no monetizado, está poco reconocido y, en consecuencia, infravalorado (Frau 2001; Carrasco, 2014; Pérez Orozco, 2014). Como señala María José Frau (2001: 114), "aquellas mujeres que desempeñan el trabajo doméstico de manera exclusiva acceden a los recursos por medio de otra persona. Son percibidas como un colectivo improductivo y dependiente, al margen de la carga de trabajo que soporten". Por lo tanto, la participación laboral de las mujeres en sectores monetizados es fundamental para su autonomía económica y personal, porque el trabajo remunerado es la principal vía para obtener los ingresos propios necesarios para satisfacer las necesidades humanas, pero también porque genera estima social y facilita el acceso a una ciudadanía plena.

\subsection{Escaso acceso a la protección contributiva}

El efecto de las prestaciones sociales del Estado del bienestar en la reducción de la pobreza y exclusión social de las mujeres ha sido, hasta la fecha, limitado. Es necesario señalar que el Estado del bienestar es una estructura que reproduce las desigualdades de género existentes en la sociedad y, en particular, en el mercado de trabajo. Esta institución, de hecho, al fundarse sobre una concepción masculina y familista del trabajo, que prevé trayectorias laborales sin interrupciones y a jornada completa (Fernández Viguera, 1998), asegura una protección insuficiente a las mujeres, cuya participación en el mercado laboral es, a menudo, fragmentada e interrumpida.

Las mujeres no acumulan la cotización necesaria para acceder a prestaciones contributivas similares a las de los hombres y deben contentarse, en numerosas ocasiones, con prestaciones asistenciales, cuyo importe es mucho menor. A esto se añade que la acción del Estado del bienestar fue pensada como complementaria, -no sustitutiva- del trabajo que las mujeres realizan de forma gratuita en los hogares (Moreno et al., 2003). Como la economía feminista ha señalado de forma reiterada, el trabajo reproductivo $y$ de cuidados que las mujeres hacen en el hogar no 
es remunerado ni contabilizado, pero facilita que los hombres puedan acceder a mayores recursos económicos a través del empleo (Valls y Belzunegui, 2014).

La falta de reconocimiento del trabajo reproductivo y de cuidados, junto con la menor participación en el mercado laboral, deja a las mujeres en una situación de vulnerabilidad, en especial cuando quedan viudas o la pareja se rompe.

\subsection{Posición en el trabajo reproductivo y de cuidados}

La posición que las mujeres ocupan en el trabajo reproductivo y de cuidados es, de hecho, la clave que permite explicar su posición en el mercado laboral y su menor acceso a las prestaciones contributivas. Las mujeres asumen el trabajo reproductivo y de cuidados necesarios para el sostenimiento de la vida humana (Robeyns, 2003), un trabajo fundamental en la economía capitalista actual, ya que sin él, el mercado no podría funcionar. Como señala Cristina Carrasco (2014: 35-36), “el trabajo de cuidados participa de manera relevante en la reproducción de la fuerza de trabajo necesaria para la producción capitalista”. Otra característica del trabajo de cuidados realizado por las mujeres "es liberar a los hombres adultos de esa responsabilidad y así facilitarles su participación en el mundo público con total libertad de tiempo y acción. Es decir, permitirles ser homo economicus".

La economía feminista señala con claridad que, por un lado, el mercado y su funcionamiento dependen de que existan los trabajos de cuidados invisibles; y por otro lado, que los hombres pueden acceder al mercado laboral de forma privilegiada gracias al trabajo oculto que realizan las mujeres en la esfera doméstica y de cuidados. En palabras de Amaia Pérez Orozco (2014: 65), “los cuidados son la base invisible de un sistema económico insostenible, entre otras cuestiones, porque se erige sobre la tensión acumulación de capital-cuidado de la vida”.

\subsection{Otros factores de desigualdad que inciden en la exclusión social}

La toma en consideración de los tres ámbitos de desigualdad hasta ahora analizados no agota, sin embargo, la explicación de los procesos de exclusión social y de empobrecimiento de las mujeres. A las causas ya mencionadas, es preciso añadir otros factores que, de forma transversal, influyen sobre el mayor riesgo de pobreza femenina. Estos factores provienen, en su gran mayoría, del contexto familiar y también de la edad (Jiménez Ramírez, 2008: 183):

Se considera que el contexto familiar constituye el ámbito primario de relaciones interpersonales y en él pueden actuar factores que acentúen sensiblemente los riesgos de exclusión (violencia familiar, monoparentalidad en situaciones de precariedad....). La edad remite a la especial incidencia de los procesos de exclusión social en las fases más vulnerables del ciclo vital (infancia, adolescencia, vejez...). El no acceso a la protección social agrava de forma determinante algunos factores ya de por sí generadores de vulnerabilidad (paro de larga duración, dependencia física en personas de edad avanzada...).

En relación con el contexto familiar, una circunstancia que agudiza la vulnerabilidad de las mujeres es su dependencia económica respecto a sus parejas y cónyuges. Dentro del hogar, las rentas procedentes del trabajo del hombre no siempre se distribuyen de forma equitativa y las mujeres no son dueñas de los ingresos que llegan a su unidad familiar. Por lo tanto, ante cualquier situación que altere este contexto familiar (ruptura de la pareja, enfermedad, muerte), se encontrarán desprotegidas y aumentará su riesgo de padecer pobreza o exclusión social.

Otro factor relacionado con el contexto familiar, en sentido amplio, es la forma en que las redes sociales y familiares de apoyo actúan como sostén vital para que las mujeres no caigan en riesgo de exclusión social o pobreza. Las mujeres que no cuentan con redes sociales o familiares que las apoyen están en una situación de mayor vulnerabilidad y sufren mayor riesgo de vivir situaciones de exclusión. A través de los testimonios de las mujeres, comprobaremos como éste es un factor de sostenimiento decisivo.

Pero, sin duda, uno de los factores de vulnerabilidad y riesgo de exclusión social más importante es la violencia de género (o violencia machista) que se ejerce contra las mujeres. La violencia de género es producto de las desigualdades de género y de la cultura patriarcal (Damonti, 2014), que existe porque “el patriarcado ha puesto en manos de los hombres un enorme poder simbólico, y también material, del que ha desposeído a las mujeres" (Gimeno Reinoso y Barrientos Silva, 2009: 40). Es decir, sin desigualdades de género, no habría violencia de género.

\section{Breve aproximación a las limitaciones de las estadísticas oficiales sobre pobreza y exclusión social desde la perspectiva de género}

Las operaciones estadísticas oficiales consultadas para conocer la pobreza y la exclusión social de la población de la CAE, y más concretamente de las mujeres, provienen tanto de fuentes estadísticas del Gobierno Vasco como del Estado español. Sometidas a una revisión desde la perspectiva de género, todas comparten limitaciones importantes que hacen que la realidad de las mujeres en situación de pobreza y exclusión social quede, en gran parte, oculta y permanezca invisibilizada.

La primera limitación identificada es que, a la hora de medir la pobreza y la exclusión social, los datos 
recogidos son sesgados y ciegos al género. La información desagregada por sexos es muy escasa: sólo se ofrece información diferenciada para hombres y mujeres de unos pocos indicadores generales. Por lo tanto, los datos ofrecidos por estas operaciones estadísticas son insuficientes para realizar una investigación en profundidad de la situación de pobreza y exclusión social en la que se encuentran las mujeres como colectivo y de sus causas. El sexo no aparece como variable transversal en la información disponible. Así, por ejemplo, es posible encontrar datos desagregados por sexo y por edad, pero de forma separada, de manera que, si deseamos relacionar ambas variables, el análisis será más complicado. El problema no es que no existan datos, sino que la variable género no se analiza en profundidad.

La segunda limitación está relacionada con la forma en que se mide la pobreza y la exclusión social tomando siempre como referencia la renta monetaria y el trabajo formal. En este sentido, la economía de mercado se ha situado en el centro del análisis de la esfera pública y mercantil, y el trabajo se ha identificado tradicionalmente con empleo remunerado, dejando invisibilizados todos los trabajos que se realizan al margen del mercado (Carrasco, 2014), en los que mayoritariamente se encuentran las mujeres; trabajos que, sin embargo, son fundamentales para la supervivencia y sostenimiento de la propia economía de mercado.

El cambio significativo que se ha producido en las últimas décadas ha sido el desarrollo de las encuestas de uso del tiempo, las cuales, sin llegar a ser operaciones estadísticas dirigidas a medir el trabajo mercantil y de cuidados, sí proporcionan información cuantitativa sobre el tiempo dedicado a los trabajos no remunerados por hombres y mujeres. En cambio, sobre el trabajo de mercado existen estadísticas oficiales, siendo la Encuesta de Población Activa, del Instituto Nacional de Estadística (INE), y la Encuesta de Población en Relación con la Actividad (PRA), del Eustat, las dos más relevantes.

En cuanto a la Encuesta de Población Activa (EPA), se puede señalar que "su finalidad principal es obtener datos de la fuerza de trabajo y de sus diversas categorías (ocupados, parados), así como de la población ajena al mercado laboral (inactivos)" (INE, 2017). Esta encuesta es una de las más importantes y que más influyen en el diseño de las políticas económicas y de empleo, ya que los principales datos del mercado laboral (tasa de actividad, tasa de empleo, tasa de desempleo) provienen de esta fuente. La EPA recoge información estadística que tiene que ver con el trabajo de mercado que realizan las personas, por lo que sus datos y sus tasas sólo miden lo que ocurre en el trabajo mercantil. Y lo mismo sucede con la Encuesta de Población en Relación con la Actividad, ya que se basa en las mismas definiciones y sigue la misma metodología.

En consecuencia, quedan invisibilizadas muchas de las actividades económicas que realizan las personas, mayoritariamente las mujeres, fuera de la esfera mercantil. Este sesgo en los datos dificulta conocer la verdadera situación sociolaboral de mujeres y hombres (Carrasco, 2014).

La tercera limitación tiene su origen en la unidad de referencia utilizada por las estadísticas que miden la pobreza y la exclusión social. La unidad de medida y análisis utilizada es el hogar y los ingresos familiares en el hogar, entendiendo que los recursos se distribuyen equitativamente entre todos los miembros de la unidad convivencial, desconsiderando así la desigualdad que se da en el reparto de los recursos entre mujeres y hombres. El hogar se conceptualiza como unidad de consumo, de redistribución interna de recursos, de creación de solidaridades y apoyos (Laparra, 2014); además, se entiende como una unidad homogénea, cuyos miembros comparten el mismo nivel de riqueza o de pobreza. Desde esta perspectiva, las desigualdades de género quedan invisibilizadas, ocultas bajo el "velo del hogar" (Valls y Belzunegui, 2014).

Sin embargo, como han señalado numerosos autores y autoras, la distribución de los recursos en el seno de la familia está lejos de ser igualitaria y equitativa (Fernández Viguera, 1992, 1998; Gaviria, Laparra y Aguilar, 1995; Gabàs i Gasa, 2003). Si a esto le sumamos que, en muchas de estas estadísticas o encuestas, no se incluyen datos desagregados por sexo, difícilmente vamos a poder analizar la realidad desde el enfoque de género.

Por último, el análisis por hogares obvia el hecho de que algunas personas dentro de este espacio son más vulnerables, por no tener ingresos propios suficientes para vivir de forma independiente. Es el caso de muchas mujeres, y también de jóvenes y ancianos.

\section{Análisis cualitativo sobre la realidad de las mujeres en situación de exclusión social}

Tal y como se indicaba en el apartado anterior, los datos estadísticos sobre exclusión social y género en la CAE no son suficientes para realizar un diagnóstico de la situación de privación de las mujeres en relación con los hombres, y para realizar un diagnóstico en profundidad necesitábamos conocer de primera mano cómo viven las mujeres sus propios procesos de empobrecimiento y exclusión. Disponer de un análisis que visibilice la realidad del colectivo de mujeres en riesgo o exclusión social es prioritario para poder diseñar políticas y programas acordes y eficaces para este colectivo.

En este sentido, como ya se ha señalado, se ha optado por aplicar la metodología cualitativa. En nuestra investigación, hemos utilizado grupos focales heterogéneos (formados por diversos perfiles de mujeres) para poder examinar las múltiples dimensiones de la exclusión y sus manifestaciones. 
En cuanto a los perfiles de mujeres en situación de vulnerabilidad o exclusión social, podemos señalar que también son perfiles diversos y heterogéneos. Nuestro acceso a estas mujeres ha sido a través de las entidades sociales de EAPN Euskadi. Son, por lo tanto, mujeres que ya están siendo atendidas por servicios socioeducativos específicos, ya sean servicios sociales públicos, ya gestionados por las propias entidades que conforman la red de EAPN Euskadi. Por consiguiente, en la mayoría de ocasiones son mujeres con las que se mantiene un contacto frecuente y continuado en el tiempo.

Los discursos y testimonios no se analizan por perfiles, sino desde la multidimensionalidad de la exclusión social y desde la interseccional, es decir, abordando que, al hecho de ser mujer en situación de pobreza, se le pueden añadir otros factores de discriminación, como ser inmigrante, ser madre soltera, o no tener empleo. Es desde este enfoque desde donde realizamos nuestro análisis.

En un primer momento, identificamos un gran interés por parte de todas las entidades de la red EAPN Euskadi, y nueve de ellas se mostraron dispuestas a participar directamente, organizando grupos de mujeres, o dándonos acceso directo a algunas de ellas. Las entidades ofrecieron su apoyo para la realización de los grupos focales, cediendo los espacios necesarios. Con cada entidad, establecimos los perfiles de mujeres a los que podríamos acceder y organizamos, con su colaboración, cada una de las sesiones del trabajo de campo. En consecuencia, las entidades han participado de manera muy directa en este estudio.

\section{5. Ámbitos y ejes que conforman los procesos de exclusión social}

Para poder realizar un análisis de la exclusión social desde la visión de género, tenemos que delimitar las diferentes dimensiones y ejes que conforman los procesos de exclusión social. A fin de examinar los diferentes problemas con los que se encuentran las mujeres en riesgo o exclusión social, hemos clasificado los factores de exclusión dentro de cuatro ámbitos o ejes (Subirats, 2004; Laparra, 2010):

- Económico: identifica las situaciones de exclusión del empleo, pobreza económica y dependencia de prestaciones sociales.

- Laboral: el análisis de los procesos de exclusión en esta esfera conlleva la necesidad de distinguir entre dos espacios, el acceso al mercado laboral (la mayor o menor condición de 'empleabilidad' de las personas), y la exclusión o vulnerabilidad social derivada de las condiciones de trabajo.

- Sociorrelacional: este eje identifica, por un lado, las situaciones de aislamiento social (escasez 0 debilidad de redes familiares, monoparentalidad, soledad, escasez o debilidad de redes sociales, rechazo o estigmatización social) y, por otro lado, la integración en redes sociales 'perversas' (deterioro de las redes familiares, aparición de conflictos o violencia intrafamiliar).

- Personal: empoderamiento, autoestima, desmotivación.

Todas las dimensiones se interrelacionan entre sí, y no se puede entender por separado, puesto que al hablar de ámbitos o ejes de exclusión social que afectan a las personas es muy difícil delimitar las fronteras entre ellos. Hay que trabajar desde la integralidad de todas las dimensiones para poder entender los diferentes procesos de exclusión, y así poder establecer mecanismos que ayuden a paliar dicha situación (Figura 1).

\section{Síntesis de los resultados extraídos de los discursos}

El análisis realizado nos ha permitido identificar una problemática compleja y diversa. Una vez ordenada toda esta información en los cuatro ámbitos de exclusión social identificados (laboral, económico, sociorrelacional y personal), pasamos a explicar y analizar, los problemas y necesidades identificados por cada ámbito de exclusión. En este análisis se incluyen testimonios de las mujeres que han participado en la investigación.

\section{1. Ámbito laboral}

Dentro del ámbito laboral, se identifican una serie de elementos que explican que las mujeres estén en una situación de mayor vulnerabilidad o riesgo de exclusión social, y que conducen a que la intensificación de la pobreza sea mayor para ellas. Estos elementos se han agrupado en dos categorías o factores: por un lado, las dificultades para acceder al mercado de trabajo y su situación laboral en condiciones precarias; $y$, por otro lado, las dificultades para acceder a una formación que les posibilite una trayectoria profesional.

A través del análisis de la información cualitativa, se pone de manifiesto que una de las mayores barreras que encuentran las mujeres para acceder a un empleo se sitúa en el trabajo reproductivo y de cuidados. Los relatos de las mujeres ponen en evidencia que la división sexual del trabajo es un elemento clave en la pobreza y vulnerabilidad de las mujeres.

Muchas mujeres han trabajado toda su vida en trabajos precarios y sin contrato, intentando compatibilizar esos trabajos informales con la responsabilidad de los cuidados. Al trabajar en la economía sumergida, obtenían unos ingresos que les ayudaban a sacar adelante a sus familias, pero esta situación -haber trabajado, pero sin cotizar y sin derechos- les ha acarreado consecuencias económicas graves, puesto que no tienen derecho 


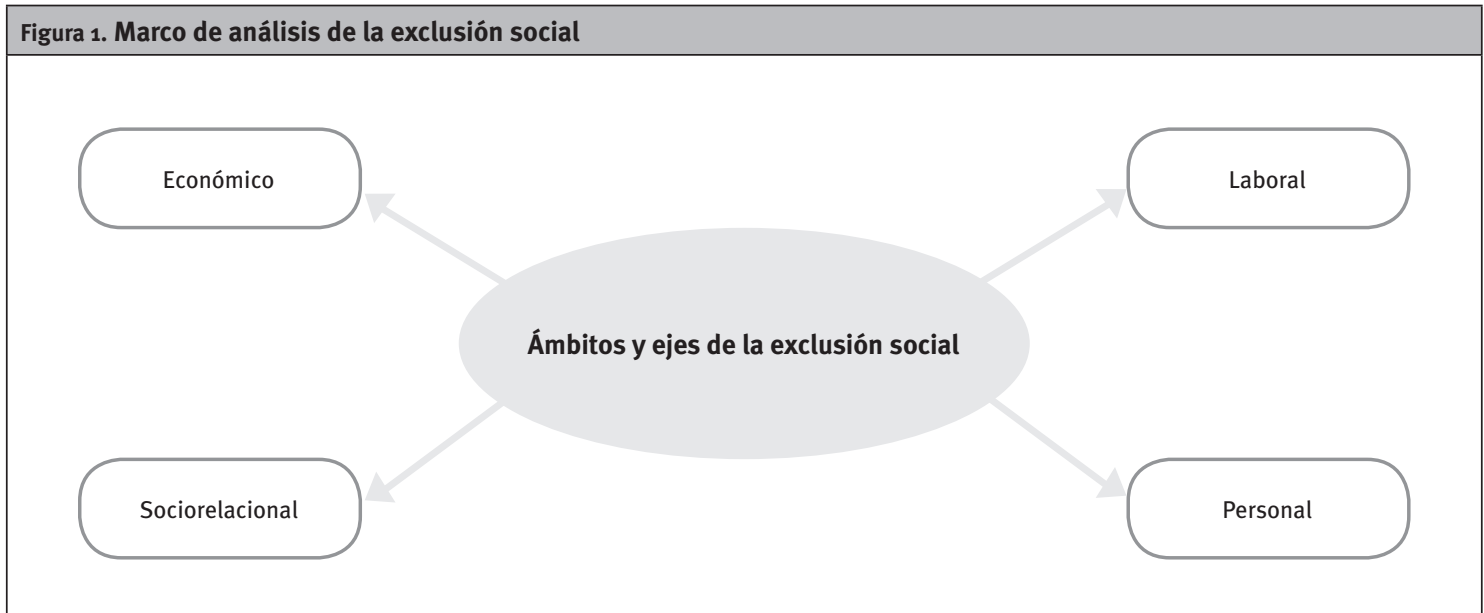

Fuente: Elaboración propia a partir de Subirats (2004) y Laparra (2010).

a ninguna prestación de desempleo, ni jubilación. En definitiva, se encuentran en una situación de absoluta desprotección:

Cuido a mi marido, a mis padres enfermos y, a veces, a mis nietos... Es difícil compaginar todo. Yo he trabajado toda la vida en casa y responsabilizándome del cuidado de mis hijos por completo..., y ahora no tengo nada... (M4).

Yo he trabajado muchos años en casas limpiando, sin contrato. Me pagaban y podía sacar adelante a mi familia, pero nunca me dieron de alta en la Seguridad Social, y ahora no tengo jubilación (M58).

En cuanto a la formación, también se ha identificado un problema de cierta frustración de las mujeres con los resultados obtenidos tras los cursos. Ellas esperan que les ayuden a encontrar un empleo estable y de calidad, pero el mercado laboral no siempre responde a esas expectativas. La mayoría de las mujeres mayores cuentan que no han tenido la oportunidad de estudiar, o que sólo tienen la educación básica. En el caso de las mujeres más jóvenes, la realidad es más heterogénea: algunas sólo han realizado estudios de primaria; otras, aunque comenzaron la secundaria, no llegaron a acabarla; y algunas, las menos, han llegado a la Universidad, pero sin acabar los estudios:

Yo hace años hice un curso del Ayuntamiento. Luego estuve trabajando de limpieza de piscinas y luego, en el albergue, pero todo eso se acabó. Estuve seis meses. Eran talleres de empleo (M23).

\section{2. Ámbito económico}

En cuanto al ámbito económico, podemos distinguir un número elevado de problemas esenciales de exclusión: la pobreza económica, las dificultades financieras del hogar, la dependencia económica de la protección social, las dificultades para poder acceder a la RGI y, por último, la dependencia económica de las mujeres hacia sus parejas. Son factores complementarios entre sí, y que nos muestran distintos grados, momentos o aspectos de la exclusión económica.

Un número importante de las mujeres participantes en los grupos focales reciben o han recibido en algún momento prestaciones sociales - por desempleo, renta de garantía de ingresos (RGI), ayudas de emergencia social (AES)-, y un número también bastante significativo complementan estas ayudas con prestaciones por discapacidad. Los relatos recogidos dejan bien clara esa dependencia de las mujeres respecto a las prestaciones sociales:

Yo cobro la pensión por discapacidad, y el complemento de RGI (M16).

Yo estoy cobrando minusvalía, con complemento de RGI y con complemento de vivienda (M52).

Yo llevo cobrando la RGI tres años, y además cobro el complemento de vivienda, y también cobro la orfandad de mis hijos, porque me he quedado viuda con tres niños muy pequeños (M39).

Aunque hablan de la insuficiencia de la prestación, del endurecimiento de requisitos para acceder a ella y del mayor control por parte de Lanbide, la RGI es vital para cubrir las necesidades básicas y, sin ella, vivirían situaciones de exclusión aún mucho más duras. Señalan que las ayudas económicas sirven para estar tranquilas y poder afrontar otros problemas personales. Les proporcionan mayor autonomía, al no depender de nadie. Les aportan cierta dignidad. Para las mujeres que reciben la RGI, es indispensable seguir recibiéndola para vivir; por eso, los testimonios sobre la RGI son positivos.

También hay testimonios de mujeres que quieren dejar de depender de las ayudas sociales para sentirme más independientes: 
La ayuda económica RGI, para mí, es una tranquilidad, porque, por lo menos, ese problema económico no lo tengo, y me deja hacer otras cosas, como ir a talleres, intentar recuperar a mis hijas, puedo ir a los juzgados, etc.... Me da mucha tranquilidad para poder dedicarme a otras cosas (M46).

Recibo la RGI, pero estoy buscando trabajo: lo que quiero es un trabajo, no recibir una ayuda; prefiero estar trabajando y dejar de depender de las ayudas... (M37).

Muchas mujeres no cumplen alguno de los requisitos que exige la Administración para poder recibir la RGI. El endurecimiento de los requisitos que se ha ido produciendo en los últimos años está dificultando gravemente el acceso de las mujeres a esta prestación social:

No tengo ni pensión ni nada, ni ayudas..., porque estoy en casa con unos familiares y no me dan RGI. El problema es que no tengo dónde ir, y sin tener otro sitio donde me pueda empadronar, no voy a poder cobrar la RGI. Es un círculo vicioso... (M63).

\section{3. Ámbito social-relacional}

Dentro del ámbito relacional, hemos incluido varios factores causales, como son la violencia machista producida en el hogar, la falta de apoyo institucional (desamparo), las situaciones de ruptura, la escasez o debilidad de redes familiares (monomarentalidad, soledad), la escasez o debilidad de redes sociales y el rechazo o estigmatización social.

Las mujeres sienten un gran apoyo de las entidades sociales, y muchas de ellas las consideran esenciales para poder salir de la situación de dependencia personal o económica en la que se encuentran. Las entidades las ayudan en los trámites legales y administrativos, y las apoyan en sus procesos de inclusión social. Les aportan apoyo psicológico y emocional. Ellas sienten que, sin las entidades, estarían en una situación muy dura.

Hay mujeres que cuentan con apoyo familiar, que las ayuda a superar situaciones complicadas. Las que no cuentan con apoyo familiar, porque no tienen familia o, como en el caso de las mujeres inmigrantes, está en sus países de origen, han tenido que recurrir a las entidades sociales para que las ayuden. En este sentido, vemos la importancia de las redes sociales de apoyo, tanto familiares como de las entidades sociales, para poder evitar situaciones de mayor vulnerabilidad, de pobreza y exclusión social. También resultan esenciales para evitar el aislamiento. Saber que cuentan con un apoyo hace a las mujeres sentirse protegidas y no tan vulnerables.

La violencia machista es otro factor de empobrecimiento de las mujeres. Casi todas las mujeres de nuestra investigación han vivido situaciones de violencia machista en algún momento de su vida, bien a través de sus parejas o bien de sus padres cuando eran niñas. Esta situación también les genera sentimientos de inseguridad y de frustración; han sufrido miedo y mucha soledad, que ha hecho que se sientan muy vulnerables y que ha afectado mucho a su autoestima, llegando incluso a situaciones de depresión o enfermedades mentales.

A través de los discursos y relatos de las mujeres, vamos visibilizando todos estos factores generadores de pobreza y exclusión social:

Me dieron la ayuda por maltrato; si no, no me la dan. Me la dieron por eso, no por tener los hijos. Además, no vale cualquier cosa, tiene que haber una denuncia, una orden de alejamiento, etc..., varios requisitos $\left(\mathrm{M}_{5}\right)$.

He intentado dos veces separarme, pero la última vez ya me dijeron que habían cambiado las leyes, y entonces yo me vi muy desamparada y no seguí adelante, me eché para atrás, porque me vi desamparada, y sin nada,... Y ¿a dónde voy? Si no tengo nada... (M62).

He ido a todos lados, he tocado todas las puertas para pedir ayuda, y nada..., nunca cumplo los requisitos: si no es por una cosa, es por otra... Siento que a nadie le importo... ¿Dónde voy? (M14).

Es que ¿dónde recurres? Es lo único que tenemos, ¡ino podemos recurrir a nadie más!! En serio, ¿dónde recurres? ¡Si es que no hay nada! (M21).

La familia me ha ayudado mucho en mi proceso de divorcio (M73).

Tengo dos hijos, uno de 23 y otro de 2 años. Me quitaron la ayuda un año entero, me ayudó mi madre, ¡sólo ella!... ¡Qué iba a hacer sin ayuda y con mis hijos a cargo yo sola!! (М30).

Tengo dos hijos y estoy divorciada... Estoy sola con mis hijos. No tengo trabajo y cobro RGI. No tengo ayuda familiar, estoy sola y es muy duro (M8).

Me siento apoyada en la entidad. Hago cursos; ahora estoy haciendo uno de informática, y cuando acabe, haré otro $\left(\mathrm{M}_{2}\right)$.

\section{4. Ámbito personal}

Dentro de este ámbito, hemos querido analizar cómo han sido sus trayectorias vitales y los procesos de desempoderamiento/empoderamiento que las mujeres han desarrollado en sus vidas. $\mathrm{El}$ empoderamiento es un factor de desarrollo de las mujeres y su falta acrecienta el riesgo de exclusión social y pobreza. 
Al realizar el análisis de la información cualitativa, observamos que las mujeres viven situaciones emocionales delicadas, como enfermedades mentales graves (suicidios, autolesiones), depresiones, falta de autoestima, sentimientos de culpa, soledad, vergüenza, impotencia, angustia, desesperanza o desesperación provocados por el desempoderamiento que les han producido las situaciones personales por las que han pasado o que están pasando en sus vidas.

Es importante destacar que estas mujeres expresan con dificultad sus sentimientos, pero sí manifiestan un gran dolor, sufrimiento, angustia, daño físico y moral. Todas las mujeres tienen una gran necesidad de ser escuchadas.

Ven muy positivamente los grupos de mujeres, destacando la importancia de encontrarse con otras mujeres en sus condiciones, puesto que para ellas, poder escuchar a otras mujeres que están en su misma situación, las ayuda a sentirse comprendidas y no juzgadas. Necesitan el grupo para evitar situaciones de aislamiento. El grupo tiene una gran incidencia en sus vidas, ya que las ayuda en sus procesos de empoderamiento y autoestima, y consiguen recuperar la confianza en sí mismas. Son mujeres que necesitan mucho apoyo emocional y psicológico.

Mi problema es la soledad, la baja autoestima también, pero sobre todo me siento muy sola.... no tengo familia aquí (M61)

Estos espacios de mujeres son importantísimos, se tienen que hacer más veces (M47).

Los grupos de mujeres son necesarios, porque oyes la experiencia de otras personas que son similares a las tuyas y entonces te ves reflejada, y te sientes comprendida y te desahogas, mucho, muchísimo (M49).

\section{Conclusiones}

La exclusión social y la pobreza que sufren las mujeres deben entenderse como algo estructural (fruto del modelo socioeconómico vigente), y no como algo propio de las personas que padecen esas situaciones. En este sentido, las mujeres parten de una posición social de desigualdad, lo que las hace más vulnerables a situaciones de exclusión. Si no se tiene en cuenta la desigual situación y posición de las mujeres a la hora de diseñar los programas de lucha contra la pobreza, estaremos abocando a las mujeres a una situación de discriminación, que las llevará a mayores niveles de vulnerabilidad y exclusión social.

No podemos olvidar las situaciones específicas que suponen un factor de vulnerabilidad añadido, como la crianza en solitario, las rupturas y separaciones, la inmigración, la edad avanzada, el consumo de drogas y las drogodependencias, o la pertenencia a una minoría étnica. Las políticas sociales serán efectivas si evitan la vulnerabilidad de las mujeres en estas condiciones.

Por todo ello, podemos señalar que el análisis de los procesos de empobrecimiento de las mujeres y el diagnóstico de las causas y factores que provocan la pobreza y exclusión social son prioritarios para plantear políticas de lucha contra la pobreza eficaces para la población. Es indispensable la creación de medidas preventivas y específicas de carácter integral, que aseguren la igualdad de oportunidades de las mujeres, garantizando el reconocimiento de sus derechos humanos y promoviendo su desarrollo e inserción social. 
BRUNET, I. (2009): "Pobreza y exclusión social desde la perspectiva de género" Revista Internacional de Organizaciones, $\mathrm{n}^{\circ}-3$, págs. 13-27 [rhttps://doi. org/10.17345/rio3.13-27〉].

BRUNET, I.; VALLS, F.; y BELZUNEGUI, A. (2008): “Pobreza, exclusión social y género", Sistema. Revista de Ciencias Sociales, n-207, págs. 69-86.

CARRASCO, C. (ed.) (2014): Con voz propia: la economía feminista como apuesta teórica y política, Madrid, Viento Sur.

DAMONTI, P. (2014): Una mirada de género a la exclusión social, serie Documentos de Trabajo del VII Informe sobre Exclusión y Desarrollo Social en España, nํㅜ 3.1, Madrid, Fundación Foessa; Cáritas Española Editores [<http://www. foessa2014.es/informe/uploaded/documentos trabajo/15102014151359_2687.pdfı].

DE LA CAL, M. L. (2009): “Avances metodológicos para el análisis y la comprensión de la desventaja social femenina", Revista Internacional de Organizaciones, $\mathrm{n}^{0} \mathbf{3}$, págs. 29-47.

EUSTAT (s/f): Encuesta de Población en Relación con la Actividad, Vitoria-Gasteiz, Instituto Vasco de Estadística [rhttp://www.eustat.eus/ estadisticas/tema_57/opt_1/ti_Encuesta_de poblacion_en_relacion_con_la_actividad/ temas.html>].

FERNÁNDEZ VIGUERA, B. (1998): “Feminización de la pobreza en Europa y procesos de exclusión social”, en HERNÁNDEZ ARISTU, J.; y OLZA, $M$. (comps.), La exclusión social. Reflexión y acción desde el trabajo social, Madrid, Eunate, págs. 315-335.

- (1992): "Pobreza, marginación y exclusión. Feminización de la pobreza", en VV.AA., La sociedad de la desigualdad: pobreza y marginación a debate,
Donostia, Tercera Prensa-Hirugarren Prentsa, págs. 77-86.

FRAU, M. J. (2001): "Trabajo femenino y procesos de empobrecimiento de las mujeres", en TORTOSA, J. M. (coord.), Pobreza y perspectiva de género, Barcelona, Icaria, págs. 113-132.

GABÀS I GASA, A. (2003): Indicadores de género contra la exclusión social. Informe sobre el fenómeno de la exclusión social, SURT-Associació de Dones per a Inserció Laboral.

GAVIRIA, M.; LAPARRA, M. y AGUILAR, M. (1995): "Aproximación teórica al concepto de exclusión”, en VV.AA., Desigualdad y pobreza hoy, Madrid, Talasa, págs. 133-200.

GIMENO REINOSO, B.; y BARRIENTOS SILVA, V. (2009): "Violencia de género versus violencia doméstica: la importancia de la especificidad", Revista Venezolana de Estudios de la Mujer, vol. 14, no 32, págs. 27-42.

GOBIERNO VASCO (2012): III Plan Vasco de Inclusión Activa (2012-2016), Departamento de Empleo y Asuntos Sociales [shttp://www.euskadi. eus/gobierno-vasco/-/plan_programa_ proyecto/16-iii- plan-vasco-de-inclusionactiva-2012-2016/>].

INE (2017): Encuesta de Población Activa, Madrid, Instituto Nacional de Estadística [<http://www.ine.es/ dyngs/INEbase/es/operacion.htm?c=Estadisti ca_C\&cid=1254736176918\&menu=ultiDatos\&i $\mathrm{dp}=1254735976595>$.

JIMÉNEZ RAMÍREZ, M. (2008): “Aproximación teórica de la exclusión social: complejidad e imprecisión del término. Consecuencias para el ámbito educativo", Estudios Pedagógicos, vol. 34 [rhttp://www.redalyc.org/articulo. oa?id=173514135010>]. 
LAPARRA, M. (coord.) (2014): "La fractura social se ensancha: intensificación de los procesos de exclusión en España durante 7 años", en LORENZO GILSANZ, F. (coord.), VII Informe sobre exclusión y desarrollo social en España, Madrid, Fundación Foessa; Cáritas Española Editores, págs. 151-255 [khttp://www.foessa2014.es/ informe/uploaded/descargas/VII_INFORME. pdf\#page $=151\rangle$.

- (2010): "El impacto de la crisis en la cohesión social o el surf de los hogares españoles en el modelo de integración de la 'sociedad líquida", Documentación Social, noำ158, págs. 97-130.

MORENO, L. et al. (2003): "Existe una 'malla de seguridad' en la Europa del sur? La lucha contra la pobreza en España, Grecia, Italia y Portugal", Revista Internacional de Sociología, vol. 61, nํㅜ 36, págs. 7-31.

NUSSBAUM, M. (2012): Crear capacidades: propuesta para el desarrollo humano, Barcelona, Paidós.
PÉREZ OROZCO, A. (2014): "Del trabajo doméstico al trabajo de cuidados", en CARRASCO, C. (ed.) (2014): Con voz propia: la economía feminista como apuesta teórica y política, Madrid, Viento Sur, págs. 49-73.

ROBEYNS, I. (2003): "Sen's capability approach and gender inequality", Feminist Economics, vol. 9, no 23, págs. 61-92.

SUBIRATS, J. (dir.) (2004): Pobreza y exclusión social. Un análisis de la realidad española y europea, Barcelona, Fundación La Caixa.

TORTOSA, J. M. (coord.) (2001): Pobreza y perspectiva de género, Barcelona, Icaria.

VALLS, F.; y BELZUNEGUI, A. (2014): La pobreza en España desde la perspectiva de género, serie Documentos de Trabajo del VII Informe sobre Exclusión y Desarrollo Social en España, no 2.3, Madrid, Fundación Foessa; Cáritas Española Editores [rhttp://www.foessa2014. es/informe/uploaded/documentos trabajo/15102014141447_8007.pdf`]. 